\title{
Effects of Epinephrine on Forearm Blood Flow and Metabolism in Man *
}

\author{
Marcel A. Baltzan, Reubin Andres, Gordon Cader, and \\ KenNeth L. ZierLeR \\ (From the Department of Medicine, The Johns Hopkins University and Hospital; the \\ Gerontology Branch, National Heart Institute; and the Baltimore City \\ Hospitals, Baltimore, $M d$.)
}

Many of the circulatory and metabolic effects of epinephrine remain in doubt despite (or perhaps, to some extent, owing to) the wide variety of experimental techniques used to examine them. There is agreement that when epinephrine is given intravenously to man, blood glucose concentration increases due to hepatic glycogenolysis (1), blood lactate concentration rises due largely to glycogenolysis in skeletal muscle (1), plasma FFA concentration rises due to lipolysis in adipose tissue (2), and blood flow through skeletal muscle is increased and this increase is sustained during continuous iv infusion (3).

However, because changes occurring during and after iv infusion need not reflect direct effects of the hormone on the target tissues (they could be secondary, for example, to release of other hormones or to altered concentrations of circulating metabolites), efforts have been made to focus on primary effects of epinephrine by other techniques, including direct injection into an artery supplying a limb, artificial perfusion of limbs, bathing excised muscle, and systemic administration to eviscerated animals. These studies, too numerous to cite here, have been reviewed by Griffith (4) and by Ellis (5). Results were widely discordant.

In many cases discrepancies may be traced to, or at least interpretation of data is made difficult by, one or more of the following defects: $a$ ) use

* Submitted for publication April 23, 1963; accepted September 17, 1964.

These studies were aided by contract Nonr-248(34) (NR 101-241) between the Office of Naval Research, Department of the Navy, and The Johns Hopkins University and by grants-in-aid from the National Institute of Arthritis and Metabolic Diseases (AM-00750) and the Muscular Dystrophy Association of America, Inc.

An abstract of this report appeared in J. clin. Invest. 1961, 40, 1022. of epinephrine preparations containing norepinephrine, $b$ ) too few subjects, $c$ ) too brief administration of epinephrine (sometimes only a single nearly instantaneous injection was used), $d$ ) lack of recognition that venous concentrations of metabolites were reduced simply by dilution by intra-arterial injection of much too large volumes of epinephrine solutions, $e$ ) injection of large amounts of epinephrine so that local effects were not those of physiological concentrations and sufficient epinephrine escaped into venous blood to produce systemic effects, just as though it had been injected intravenously in the first place, $f$ ) inattention to site of venipuncture, so that some venous samples may have come from blood draining mostly muscle $(6), g$ ) use of imprecise or insensitive analytical methods, $h$ ) failure to consider errors caused by misapplication of the Fick principle to nonsteady states $(7), i)$ use of arteriovenous differences alone as reflections of net uptake or output of metabolites, that is, failure to consider changes in blood flow produced by epinephrine, and $j$ ) use of heparin to flush venous catheters, leading to erroneous estimates of FFA metabolism.

Although our own studies may not be free of defects, we have eliminated to a high degree those listed above, and although we do not necessarily resolve all reported discrepancies, we offer data that may substitute for them and can be interpreted with somewhat greater simplicity. With techniques described previously in studies of metabolism of the forearm (8), we have administered epinephrine into the brachial artery at low dose and at constant rate for sufficiently long to reach a new steady state without producing systemic effects. Our studies demonstrate that epinephrine produces sustained increase in forearm blood flow, no significant effect on peripheral 
glucose uptake, marked increase in lactate production, potassium uptake by muscle, and release of free fatty acids by forearm adipose tissue. With the exception of the effect of epinephrine on blood flow, these results ought not to have been unexpected, since they agree with the weight of previous evidence of epinephrine action in other settings. They do, however, disagree with some previous reports of intra-arterial effects of epinephrine in man.

\section{Methods}

Seventeen men and six women were studied. Nine were convalescing from acute illnesses; 14 were medical students or hospital employees. Ages ranged from 20 to 73 years. All experiments were performed in the late morning, some 16 hours after the previous meal, at a room temperature of $25^{\circ} \mathrm{C}$.

Techniques and analytical methods have been described $(8,9)$. Briefly, blood flow was measured by indicator dilution, glucose by a glucose oxidase method, lactic acid by a lactic dehydrogenase method, $\mathrm{K}$ by flame photometry, and FFA by the extraction and titration method of Dole.

Blood from deep and superficial forearm veins was collected through polyethylene catheters. Arterial blood was collected through the inner lumen of a double-lumen indwelling arterial needle. Continuous injection of a solution of Evans blue dye, without or with epinephrine, was made by an infusion pump through the outer lumen. Before epinephrine injection several sets of blood samples were obtained during a control period of 30 to 60 minutes. These samples were obtained during infusion of dye solution, $1.2 \mathrm{mg}$ per $\mathrm{ml}$ isotonic $\mathrm{NaCl}$ at a rate of 0.15 to $0.34 \mathrm{ml}$ per minute. In all cases the hand was excluded from the circulation by a sphygmomanometer cuff applied about the wrist and inflated to a pressure of at least $200 \mathrm{~mm} \mathrm{Hg}$. During the control period either the cuff was inflated 5 minutes before and deflated immediately after each collection, or it was inflated 5 minutes before the first collection and maintained until the end of the last control collection. The long period of inflation of the wrist cuff (30 to $35 \mathrm{~min}$ utes) had little effect on blood flow or on forearm metabolism and induced only mild discomfort in the subjects. They were instructed not to exercise the forearm or hand muscles during the experiment.

Two types of epinephrine were administered. In the first 13 studies, done between November 1957 and April 1958 , a commercial solution of synthetic $l$-epinephrine bitartrate 1 containing, according to the manufacturer, $100 \mathrm{mg}$ epinephrine base, $0.5 \mathrm{~g}$ chlorbutanol, $0.6 \mathrm{~g}$ sodium chloride, and less than $0.2 \mathrm{~g}$ sodium bisulfite, all per 100 $\mathrm{ml}$, was diluted immediately before use in isotonic $\mathrm{NaCl}$ to a final concentration of $2 \mu \mathrm{g}$ of epinephrine per $\mathrm{ml}$.

\footnotetext{
${ }^{1}$ Suprarenin, Winthrop Laboratories, New York, N. Y.
}

It was infused through a motor-driven glass syringe at a rate sufficient to deliver $0.002 \mu \mathrm{g}$ epinephrine base per $\mathrm{kg}$ body weight per minute. The usual injection rate therefore was 0.05 to $0.08 \mathrm{ml}$ per minute. At the desired time, at a turn of a stopcock, epinephrine solution was added to the inflowing dye solution. Because the mean transit time of solution from the stopcock to the end of the arterial needle was 1 minute, zero time was taken to be 1 minute after the turn of the stopcock.

When certain unexpected results were obtained, especially with respect to forearm blood flow, a second type of epinephrine preparation was used in the last six experiments, done between September 1958 and March 1959. Synthetic $l$-epinephrine bitartrate powder ${ }^{2}$ was made up immediately before use to a final concentration of $0.7 \mu \mathrm{g}$ per $\mathrm{ml}$ in isotonic $\mathrm{NaCl}$ containing 0.5 $\mathrm{mg}$ per $\mathrm{ml}$ ascorbic acid and $1.2 \mathrm{mg}$ per $\mathrm{ml}$ of Evans blue dye. The rate of epinephrine administration in five subjects was also $0.002 \mu \mathrm{g}$ per $\mathrm{kg}$ per minute. The sixth subject was given $0.0057 \mu \mathrm{g}$ per $\mathrm{kg}$ per minute intra-arterially.

When the results of this experiment with a larger infusion of epinephrine suggested a dissociation between certain metabolic and vascular effects, during the last three months of 1963 , three subjects were given epinephrine (synthetic $l$-epinephrine bitartrate) intra-arterially at a rate of 0.02 (two subjects) or 0.025 (one subject) $\mu \mathrm{g}$ per $\mathrm{kg}$ per minute, about ten times the rate employed in most of the experiments.

To examine whether any of the responses to intraarterial infusion of epinephrine were mediated by the interaction between epinephrine and some site remote from the forearm, epinephrine (synthetic l-epinephrine bitartrate) was infused at constant rate intravenously, $0.002 \mu \mathrm{g}$ per $\mathrm{kg}$ per minute. This was the rate used in 18 of the experiments in which it was infused intraarterially.

The epinephrine infusion period in all but one subject varied from 12 to 32 minutes. In one subject pressure in the wrist cuff was released at the twentieth minute, reapplied at the thirtieth minute, and maintained for the next 30 minutes; the epinephrine infusion continued throughout the 60 minutes. In all other subjects the wrist cuff was kept inflated throughout the period of epinephrine infusion, which averaged 26 minutes.

Calculation of the quantity of metabolite used or produced. We have considered in detail previously (6-9) the complexities of the forearm with respect to the variety of tissues present, their vascular supply, and their differences in metabolism. Since the dye-dilution method for measuring blood flow gives a single value for total forearm blood flow and does not separate flow to deep and superficial tissues, net metabolite movement into and out of these tissues cannot be calculated simply from the product of blood flow and a-v concentration difference. Nevertheless by applying a correction factor, calculated as follows, forearm muscle metabolism can be estimated. Muscle constitutes about $60 \%$ of the

\footnotetext{
2 Winthrop-Stearns $301 \mathrm{RH} 26$.
} 

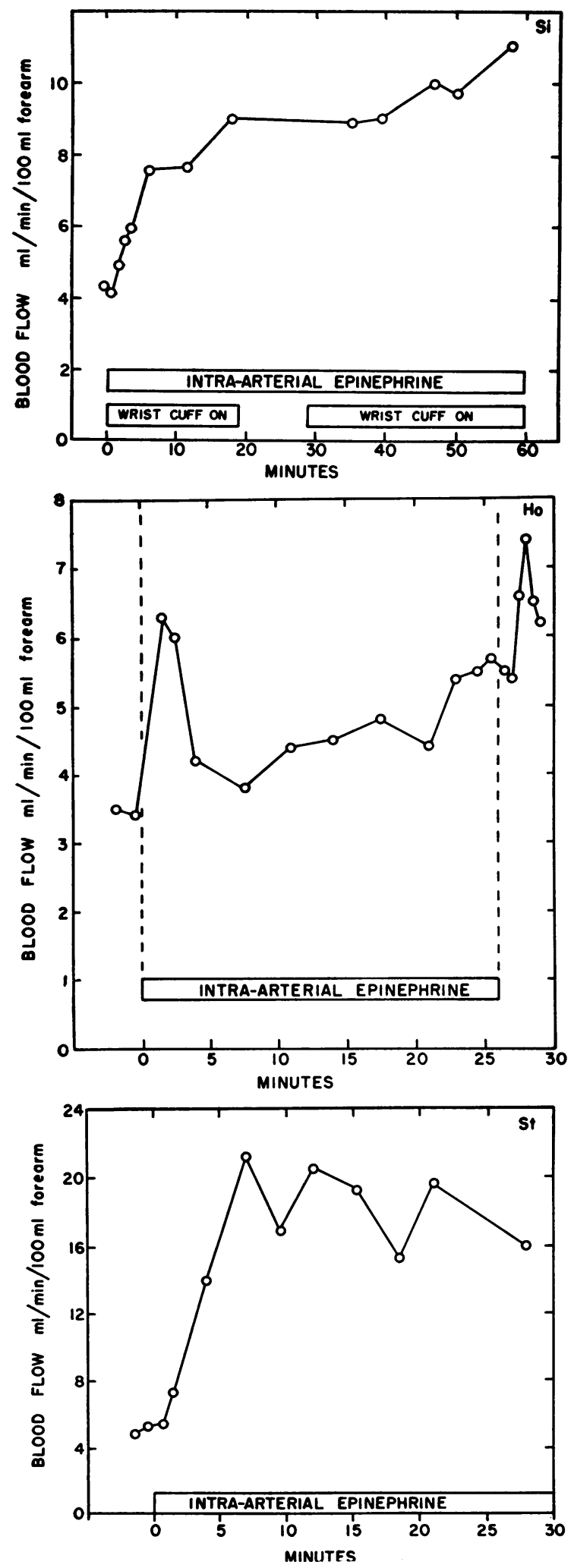

Fig. 1. A, B, C. Variations in individual ReSPONSES TO SMALL DOSE OF INTRA-ARTERIAL EPINEPHRINE. forearm mass and receives about $84 \%$ of total forearm blood flow (8) under basal conditions in the steady state at an ambient temperature of $25^{\circ} \mathrm{C}$. The correction factor is, therefore, $0.84 / 0.6=1.4$, and $\dot{Q}=1.4$ $\mathrm{F}(\mathrm{a}-\mathrm{dv}$ ), where $\dot{Q}$ is uptake (or output if $d v>a$ ) per $100 \mathrm{~g}$ forearm muscle, $\mathrm{F}$ is blood flow, in $\mathrm{ml}$ per minute per $100 \mathrm{ml}$ forearm, a and $\mathrm{dv}$ are arterial and deep venous concentrations, respectively, and 1.4 is the correction factor in units of milliliters per gram.

During intra-arterial epinephrine infusion, however, the fraction of forearm blood flow perfusing muscle must increase. Barcroft and Swan (3) found that brachial arterial epinephrine infusion reduces blood flow to the hand by $74 \%$. Presumably, therefore, it reduces blood flow to skin in general by an appreciable amount.

In our experiments, from the tenth to thirtieth minute of epinephrine infusion, brachial arterial flow increased on the average by $100 \%$. If blood flow to superficial tissues were obliterated, as can occur with epinephrine iontophoresis (3), the correction factor would be $1.00 / 0.60=1.67$, instead of 1.4 as used during the control period. On the other hand, if blood flow to the superficial tissues were not affected by epinephrine at all, so that, in absolute value, it was the same as during the control period, then muscle blood flow would have increased by $119 \%$ to yield the observed total forearm increase of $100 \%$, and muscle blood flow would represent $92 \%$ instead of the control $84 \%$ of total forearm flow. The correction factor would be 1.53. Between these extremes of 1.53 and 1.67 we have arbitrarily chosen a correction factor of 1.6, obtained on the assumption that flow through the superficial forearm bed decreased by $50 \%$. The error in the correction factor due to any error in this assumption cannot be greater than $5 \%$ and is probably less than $3 \%$.

Unfortunately, the very considerations that help us estimate flow through muscle emphasize our ignorance of flow through the superficial bed and of its quantitative changes. We can supply data only on arterialsuperficial venous (a-sv) differences in concentration. If a-sv differences are unchanged or narrow in the face of an almost certain decrease in blood flow, metabolic rates have decreased. But if a-sv differences increase with epinephrine infusion, in the absence of a measure of the magnitude of decrease in blood flow to that area, no conclusion can be reached.

\section{Results}

We shall present first the results of experiments in which epinephrine was infused intra-arterially at the smallest rate, $0.002 \mu \mathrm{g}$ per $\mathrm{kg}$ body weight per minute, in each of 18 subjects. Data on the five women in this group were not different in any respect from those of the men; the data on men and women are therefore combined. In one man, subject $\mathrm{Cu}$, for whom data are presented 
separately, there was marked maldistribution of epinephrine to forearm tissues. Complete sets of data are not available for the remaining 17 subjects in this group for the following reasons: In one subject metabolites were measured in deep venous blood only, and in another subject, in superficial venous blood only. In the first four subjects glucose analyses by the glucose oxidase method were unreliable owing to interference with color development caused by phenol in the commercial heparin solution used to fill the dead space of the collection syringe. Results on glucose metabolism are therefore limited to 13 subjects. Furthermore, it was not always possible to collect blood samples of sufficient volume at the desired time intervals to accomplish all analyses.

Blood flow. In the pre-epinephrine control period, blood flow was stable. Mean flow 1 hour before the start of epinephrine was $4.0 \mathrm{ml}$ per minute per $100 \mathrm{ml}$ forearm. Thirty minutes later it was still 4.0 , and immediately before the onset of epinephrine flow it averaged 3.9. Mean flow before epinephrine administration was 3.93 , and the mean increase in flow from the tenth minute of injection until the end of injection was 3.97 $\mathrm{ml}$ per minute per $100 \mathrm{ml}$ forearm, that is, flow doubled.

An increase in flow occurred in most subjects within 2 to 3 minutes of the beginning of epinephrine injection. Subsequently, several flow patterns were seen: $a$ ) four subjects had a progressive increase in flow (Figure 1A), b) seven subjects had a rise followed by a fall that reached the control value in only one case, $c$ ) four subjects had an initial rise followed by a fall, then a secondary rise (Figure $1 \mathrm{~B}$ ), and $d$ ) one subject had essentially no change in flow despite clearcut metabolic effects of epinephrine. In one of the 17 subjects flow could not be calculated because the dye concentrations in the two veins failed to agree within the limits previously set (10).

In subject St (Figure 1C) blood flow oscillated. This may have been a result of the experimental design and will be discussed later.

Immediate effects produced by stopping epinephrine were studied in four subjects who showed a transient further increase in blood flow when epinephrine was discontinued (Figure 1B). In eight subjects flow was measured 20 to $40 \mathrm{~min}$ -

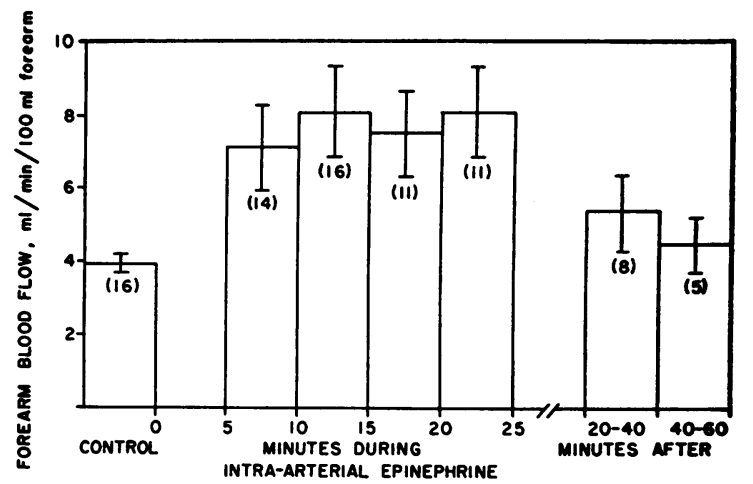

FIG. 2. FOREARM BLOOD FLOW (MEAN \pm STANDARD ERROR OF MEAN, NUMBER OF SUBJECTS IN PARENTHESES) BEFORE, DURING, AND AFTER SMALL DOSE OF EPINEPHRINE INTRA-ARTERIALLY.

utes after the epinephrine infusion had been discontinued; in three of these, flow had returned to the pre-epinephrine level; in five, flow was still significantly increased. In five subjects blood flow was measured as long as 40 to 60 minutes following the end of the epinephrine infusion; in only one of these was flow definitely above basal levels.

Although flow patterns varied in individual subjects, for the entire group flow was significantly greater than the control value $(p<0.05)$ at all time intervals from the second to the twenty-fifth minute of the infusion (Figure 2). Furthermore, the mean flow was reasonably constant from the tenth to the twenty-fifth minute. This fact, together with constant arterial concentrations of metabolites, justifies calculation of net movement of metabolites from the product of blood flow and a-v metabolite concentration difference; a new steady state had been established with respect to flow, although not in all subjects. $\dot{Q}$ was calculated from $\mathrm{F}$ at the time of each individual $\mathrm{a}-\mathrm{v}$

TABLE I

Added epinephrine concentration in forearm blood

\begin{tabular}{|c|c|c|c|c|}
\hline & \multicolumn{4}{|c|}{ Minutes after start of infusion } \\
\hline & $6-10$ & $11-15$ & $16-20$ & 21-25 \\
\hline Deep bed & $\begin{array}{c}\mu g / L \\
4.35 \pm 0.81 \\
(16) \dagger\end{array}$ & $\begin{array}{c}\mu g / L \\
3.86 \pm 0.64 \\
(16)\end{array}$ & $\begin{array}{c}\mu g / L \\
3.47 \pm 0.56 \\
(13)\end{array}$ & $\begin{array}{c}\mu g / L \\
3.68 \pm 0.52 \\
(12)\end{array}$ \\
\hline Superficial bed & $\begin{array}{c}4.69 \pm 0.78 \\
(15)\end{array}$ & $\begin{array}{c}4.32 \pm 0.65 \\
(17)\end{array}$ & $\underset{(12)}{3.68 \pm 0.54}$ & $\begin{array}{c}3.21 \pm 0.52 \\
\text { (11) }\end{array}$ \\
\hline
\end{tabular}

* I standard error of the mean.

$t$ Figures in parentheses are numbers of subjects. 
TABLE II

Effect of epinephrine on arterio-venous differences

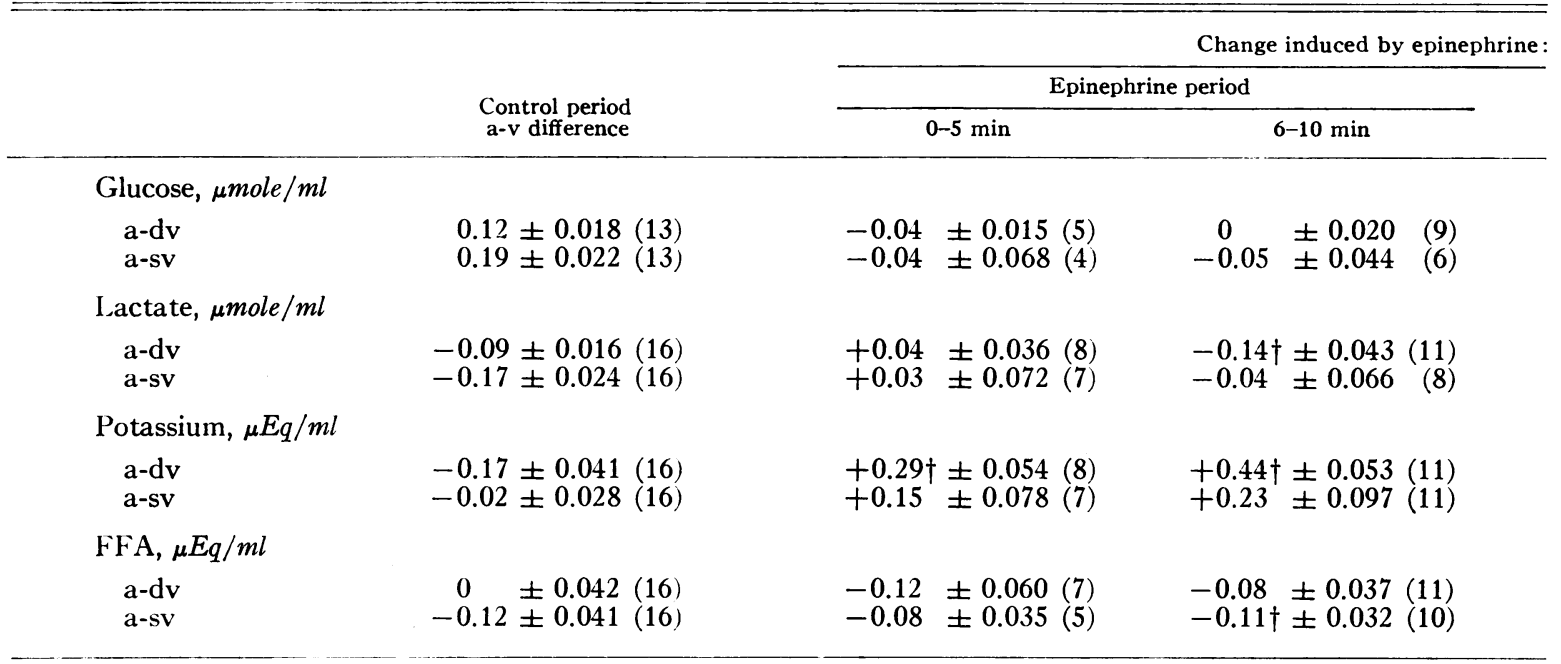

* a-dv and a-sv represent arterio-deep venous and arterio-superficial venous differences in concentration. All values are means \pm standard errors of the means. Numbers in parentheses are number of subjects on whom analyses were done. Values during the epinephrine and postepinephrine periods represent changes in a-v differences from the control values of the individuals in that group. Control values are calculated from the mean of all pre-epinephrine values obtained on each subject.

$\dagger$ Numbers that very probably differ from control values $(p<0.01)$.

difference, not as the product of mean $\mathrm{F}$ and mean a-v.

Epinephrine concentration added to arterial plasma. Despite constant rate of infusion of epinephrine, the concentration of epinephrine achieved in arterial plasma fluctuated, since arterial concentration must vary inversely with forearm plasma flow. After the tenth minute, however, the average concentration of epinephrine appeared constant (Table I). Concentrations of epinephrine perfusing the vascular beds drained by the

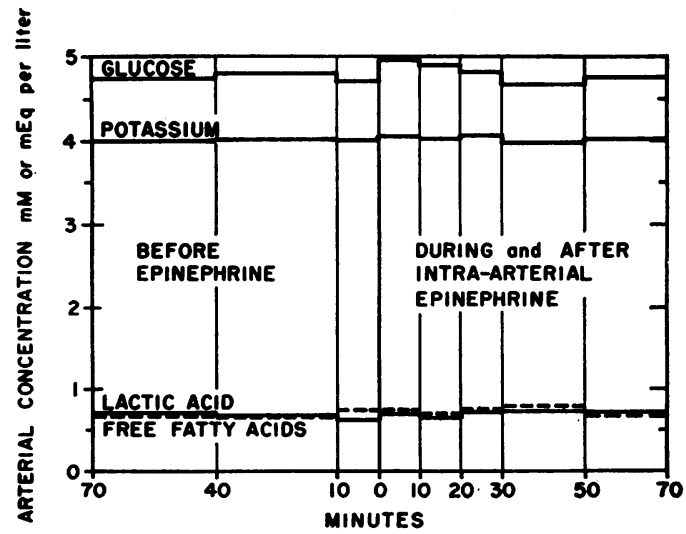

Fig. 3. LACK OF SYSTEMIC EFFECT OF INTRA-ARTERIAI EPINEPHRINE. Stability of arterial concentrations of glucose, potassium, lactic acid, and free fatty acids. deep vein and by the superficial vein were calculated individually from the degree of dilution of Evans blue dye in the venous plasma. Recirculating exogenous epinephrine was disregarded, since several factors combine to make it negligible: a) $70 \%$ of the epinephrine is removed in single passage through the forearm vascular bed (11), $b)$ the half-life of epinephrine in plasma is only 1 to 2 minutes (12), and $c$ ) intravenous infusion of $0.002 \mu \mathrm{g}$ per $\mathrm{kg}$ body weight per minute would be expected to increase the plasma concentration by only about $0.01 \mu \mathrm{g}$ per $\mathrm{L}$ according to Vendsalu's observations (11). The increase beyond endogenous epinephrine concentration in arterial plasma produced by intra-arterial infusion is $E_{A}=E_{I}\left(D_{V}-D_{A}\right) /\left(D_{I}-D_{V}\right)$, where $E$ and $D$ are epinephrine and dye concentrations, respectively, and subscripts A, I, and V refer to arterial plasma, injectate, and venous plasma, respectively. This dye dilution factor has been derived previously (9). Epinephrine concentrations in deep and superficial forearm beds were, of course, similar because dye concentrations in the two beds were similar. In general there were no systematic differences between epinephrine concentrations added to the deep and superficial forearm beds, ultimate concentrations being about 3 to $4 \mu \mathrm{g}$ per L 
TABLE II

of glucose, lactate, potassium, and free fatty acids*

\begin{tabular}{|c|c|c|c|c|}
\hline \multicolumn{3}{|c|}{ Epinephrine period } & \multicolumn{2}{|c|}{ Postepinephrine period } \\
\hline $11-15 \mathrm{~min}$ & $16-20 \mathrm{~min}$ & $21-25 \mathrm{~min}$ & $20-40 \mathrm{~min}$ & $41-60 \mathrm{~min}$ \\
\hline $\begin{array}{l}-0.04 \pm 0.028(12) \\
-0.05 \pm 0.044(12)\end{array}$ & $\begin{array}{ll}-0.02 & \pm 0.042 \\
-0.04 & \pm 0.072\end{array}$ & $\begin{array}{l}-0.06 \pm 0.040 \\
-0.04 \\
\pm 0.046\end{array}$ & $\begin{array}{l}-0.02 \pm 0.027(11) \\
-0.02 \pm 0.035(10)\end{array}$ & $\begin{array}{l}-0.01 \\
-0.10\end{array}$ \\
\hline $\begin{array}{l}-0.29 \dagger \pm 0.056(14) \\
-0.17 \dagger \pm 0.042(15)\end{array}$ & $\begin{array}{l}-0.43 \dagger \pm 0.077(10) \\
-0.10 \pm 0.079\end{array}$ & $\begin{array}{l}-0.37 \dagger \pm 0.103 \\
-0.23 \dagger \pm 0.068\end{array}$ & $\begin{array}{l}-0.16 \dagger \pm 0.038(11) \\
-0.10 \dagger \pm 0.022(10)\end{array}$ & $\begin{array}{l}-0.06 \\
+0.03\end{array}$ \\
\hline $\begin{array}{l}+0.59 \dagger \pm 0.086(14) \\
+0.22 \dagger \pm 0.066(12)\end{array}$ & $\begin{array}{l}+0.70 \dagger \pm 0.133 \\
+0.07 \pm 0.072\end{array}$ & $\begin{array}{l}+0.65 \dagger \pm 0.120(11) \\
+0.20 \pm 0.103\end{array}$ & $\begin{array}{l}+0.19 \dagger \pm 0.052(11) \\
+0.05 \pm 0.043(10)\end{array}$ & $\begin{array}{l}+0.03 \pm 0.105(5) \\
-0.04 \pm 0.011(5)\end{array}$ \\
\hline $\begin{array}{l}-0.12 \dagger \pm 0.039(14) \\
-0.21 \dagger \pm 0.083(11)\end{array}$ & $\begin{array}{l}-0.16 \dagger \pm 0.042(11) \\
-0.26 \dagger \pm 0.037(10)\end{array}$ & $\begin{array}{l}-0.16 \dagger \pm 0.032(12) \\
-0.17 \dagger \pm 0.036(9)\end{array}$ & $\begin{array}{l}-0.08 \dagger \pm 0.025(11) \\
-0.11 \pm 0.074(10)\end{array}$ & $\begin{array}{l}-0.08 \pm 0.047(5) \\
-0.21 \pm 0.081(5)\end{array}$ \\
\hline
\end{tabular}

of plasma. This is smaller than has usually been produced in man in studies of epinephrine effect on blood flow and very much smaller than the concentrations usually used in vitro.

Absence of systemic effects. Figure 3 shows the stability of the arterial concentrations of glucose, lactate, FFA, and potassium during and after the epinephrine infusion. Systemic counterregulatory mechanisms were thus avoided, and an underlying assumption of the Fick principle, the presence of a steady state, was not violated (7).

Glucose uptake (Table II and Figure 4). During the control period, a-sv glucose differences exceeded a-dv, as reported previously (13). Epinephrine caused an increase in glucose concentration in both veins, so that $a-v$ differences decreased. This decrease was present at all time intervals in both veins but was small and not statistically significant. Since the relative increase in blood flow exceeded the relative fall in a-dv difference, glucose uptake increased from $0.70 \mu$ mole per minute per $100 \mathrm{~g}$ forearm muscle in the control period to 1.21 during the epinephrine infusion, an increase of $0.51 \pm 0.32$. Although this increase is not statistically significant, glucose uptake clearly did not decrease.

Lactate production (Table II and Figure 4).
During the control period lactate concentration was higher in venous than in arterial blood, and as previously reported (6), the a-sv difference significantly exceeded the a-dv difference. An epinephrine effect was evident earlier and was more pronounced in $\mathrm{dv}$ than in sv. Lactate output in the control period could account for $32 \%$ of

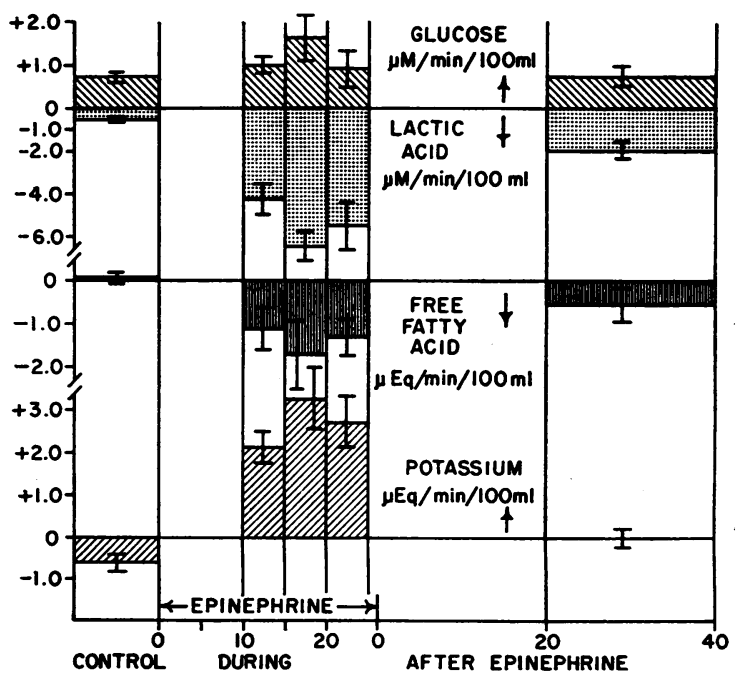

Fig. 4. UPtake (OR OUTPUT, FOR NEgative values) BY FOREARM OF GLUCOSE, LACTIC ACI, FREE FATTY ACIDS, AND POTASSIUM IN RESPONSE TO INTRA-ARTERIAL EPINEPHRINE, MEAN \pm STANDARD ERROR OF MEAN. 
TABLE III

Per cent of glucose uptake accounted for by lactate production

\begin{tabular}{lccccccccc}
\hline \hline & & \multicolumn{4}{c}{ Epinephrine period } & \multicolumn{3}{c}{ Postepinephrine } \\
\cline { 2 - 9 } & $\begin{array}{c}\text { Control } \\
\text { period }\end{array}$ & $\begin{array}{c}0-5 \\
\text { min }\end{array}$ & $\begin{array}{c}5-10 \\
\min \end{array}$ & $\begin{array}{c}10-15 \\
\min \end{array}$ & $\begin{array}{c}15-20 \\
\min \end{array}$ & $\begin{array}{c}20-25 \\
\min \end{array}$ & & $\begin{array}{c}20-40 \\
\min \end{array}$ & $\begin{array}{c}40-60 \\
\min \end{array}$ \\
\hline Deep vein & 32 & 24 & 109 & 206 & 266 & 258 & 103 & 104 \\
& $(13)^{*}$ & $(5)$ & $(9)$ & $(12)$ & $(8)$ & $(8)$ & $(11)$ & $(4)$ \\
Superficial vein & 43 & 32 & 72 & 113 & 85 & 99 & 72 & 58 \\
& $(13)$ & $(4)$ & $(5)$ & $(12)$ & $(5)$ & $(8)$ & $(10)$ & $(3)$ \\
\hline
\end{tabular}

${ }^{*}$ Numbers of subjects on whom analyses were done.

the glucose uptake in the deep forearm tissues or, to reverse the frame of reference, glucose uptake during the control period was more than adequate to account for lactate production. However, during the epinephrine infusion, lactate production was so large that glucose taken up simultaneously from blood could not have been the source of the lactate. We conclude that glycogenolysis was stimulated (Table III).

In the superficial bed, $43 \%$ of glucose uptake could be accounted for by lactate output in the control period. Similar but less striking epinephrine effects were observed here. During the last 15 minutes of the infusion, nearly all the glucose uptake could be assigned to lactate output. This experimental technique of course does not preclude an increase in glycogenolysis; it can only be stated that the net effect showed a lactate output that equaled the uptake of glucose.

Potassium (Table II and Figure 4). Potassium concentration in deep venous blood from the forearm exceeds that in arterial blood in the morning with the subject at rest in the basal state (14). These observations were confirmed as were those that showed no significant difference between arterial and superficial venous $K$ concentration (6). During epinephrine administration the direction of net $\mathrm{K}$ movement in the deep tissues reversed. Within the first 5 minutes after onset of epinephrine infusion, a-dv $\mathrm{K}$ difference shifted from $-0.2 \mu \mathrm{Eq}$ per $\mathrm{ml}$ by $+0.3 \mu \mathrm{Eq}$ per $\mathrm{ml}$, and it continued to increase by $+0.7 \mu \mathrm{Eq}$ per $\mathrm{ml}$. a-sv $\mathrm{K}$ difference increased by a smaller amount, 0 to $+0.2 \mu \mathrm{Eq}$ per ml. At the peak of the epinephrine effect, deep forearm tissues, presumably mostly muscle, extracted more than $15 \%$ of the $\mathrm{K}$ delivered to them. Nothing in these experiments illuminates the mechanism by which epinephrine causes $K$ uptake except that it is clearly independent of glucose uptake.

Fatty acids (Table II and Figure 4). FFA concentration in superficial venous plasma exceeded that in arterial, and there was no difference between arterial and deep venous FFA concentration, confirming earlier observations (6). It has been suggested that this latter observation may occur because adipose tissue, associated intimately with muscle and so drained by the deep venous system of the forearm, releases FFA into venous blood while muscle removes it from arterial blood (6). During epinephrine infusion FFA concentration in plasma from both veins rose, so that the concentration in the sv was about $50 \%$ higher than the arterial, and the dv concentration was about $25 \%$ higher than arterial. The combination of the increased negative a-v difference and increased blood flow makes it certain that FFA release from forearm adipose tissue, deep and superficial, was increased by epinephrine, as expected from in vitro studies on adipose tissue $(15,16)$ and by changes in venous FFA concentration in man after subcutaneous or iv epinephrine administration $(13,17)$. From our studies it is not possible to state whether epinephrine has an effect on FFA uptake by muscle, since under these conditions this process cannot be calculated independently from the FFA release from adipose tissue.

Lack of effect of iv epinephrine. If none of the epinephrine infused intra-arterially were removed by the forearm and all of it entered the general circulation, the effect would have been as though epinephrine had been administered intravenously. If any of the effects reported in response to intra-arterial infusion were in reality secondary to some remote action of epinephrine or to some 
metabolite of epinephrine, then these responses should occur explicitly when epinephrine is infused at the same rate intravenously. Accordingly, in two subjects epinephrine was infused into a contralateral antecubital vein for 22 or 24 minutes at a rate of $0.002 \mu \mathrm{g}$ per $\mathrm{kg}$ body weight per minute. In one subject measurement of blood flow was unsatisfactory. In the other, subject $\mathrm{Ba}$, there was no change in forearm blood flow during or after the infusion (Figure 5). In neither subject was there any change in arterial concentration of glucose, lactic acid, K, or FFA (Figure 6), and in neither subject was there any change in $a-v$ difference of any of these metabolites. Since neither blood flow nor $a-v$ differences altered in

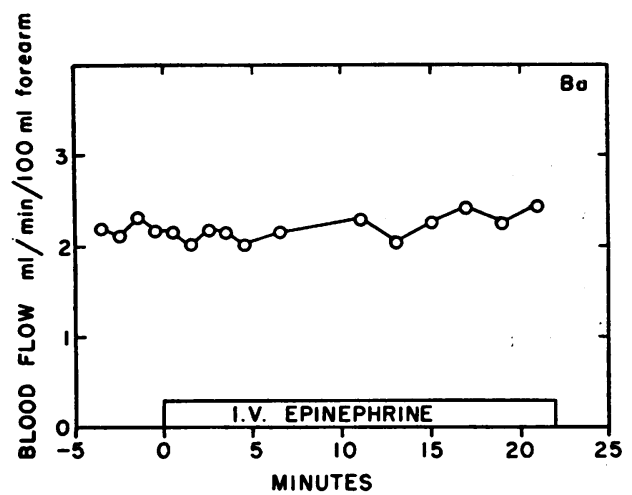

Fig. 5. LACK OF RESPONSE OF A SINGLE SUBJECT TO INTRAVENOUS EPINEPHRINE IN SAME SMALL DOSE AS GIVEN intra-ARTERIally. Compare Figure 1.

subject $\mathrm{Ba}$, there was no effect of epinephrine in forearm uptake or output of any of these metabolites.

Effects of larger rates of intra-arterial infusion. In four subjects epinephrine was infused intraarterially at the following rates ( $\mu \mathrm{g}$ per $\mathrm{kg}$ body weight per minute) : 0.0057 in one, 0.02 in two, and 0.025 in one. Blood flow was measured in three. In all three there was a transient increase in blood flow, reaching its peak in 2,4 , and 6 minutes respectively, followed by a fall to preepinephrine values in one and to one-half to onethird pre-epinephrine values in two, where it stayed for the remaining 22 to 26 minutes of epinephrine infusion (illustrated in Figure 7). Since blood flow decreased or remained unchanged during the last 15 to 20 minutes of infusion and since the rates of infusion were from approximately three to ten times that of the smaller rate re-

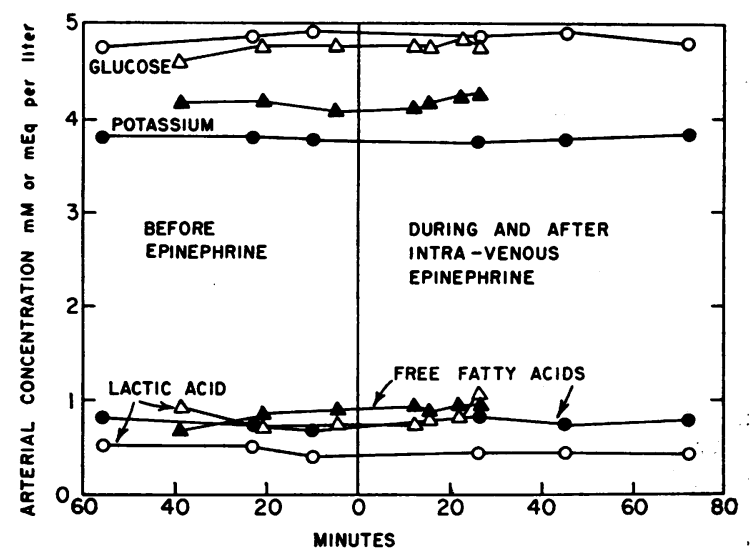

Fig. 6. LACK OF SYSTEMIC EFFECT OF INTRAVENOUS EPINEPHRINE INFUSED FOR 22 OR 24 MINUTES AT A RATE OF $0.002 \mu \mathrm{G}$ PER KG BODY WEIGHT PER MINUTE IN TWO SUBJECTS. Open and filled circles are data from one subject; open and filled triangles are data from the second subject.

ported above, the concentration of epinephrine added to arterial plasma was actually at least ten times the average concentration added in the veins of the subject who received the smaller quantity.

It might be expected that a larger fraction of the epinephrine injected intra-arterially at these greater rates would escape into the general circulation than occurred in the case of the smaller rates of injection, and that some changes in ar-

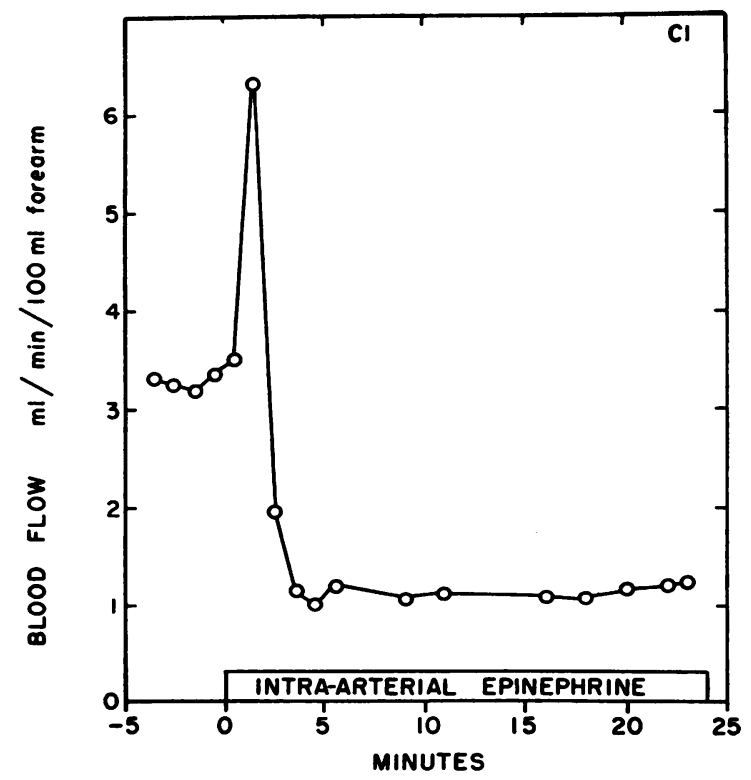

Fig. 7. EFFect OF LARGE INTRA-ARTERIAL DOSE OF EPINEPHRINE IN A SINGLe SUBJECT. Compare Figure 1. 
TABLE IV

Metabolic effects of vasoconstricting dose of epinephrine*

\begin{tabular}{lcc}
\hline \hline & \multicolumn{1}{c}{$\Delta(\mathrm{a}-\mathrm{v})$} & $\Delta \dot{\mathrm{Q}}$ \\
\hline & \multicolumn{1}{c}{$/ \mathrm{ml}$} & $/ \mathrm{min} / 100 \mathrm{ml}$ forearm \\
Glucose & $+0.09 \mu$ mole & $+0.24 \mu$ mole \\
Lactate & $-1.62 \mu$ moles & $-3.64 \mu$ moles \\
Potassium & $+1.47 \mu \mathrm{Eq}$ & $+1.51 \mu \mathrm{Eq}$ \\
FFA & $-0.20 \mu \mathrm{Eq}$ & \\
\hline
\end{tabular}

* Figures represent mean increase (more positive or less negative) or decrease (more negative or less positive) in a-dv differences (glucose, lactate, and $K$ ) in four subjects, in $\dot{Q}$ in three subjects, and in a-sv differences (FFA) in three subjects, comparing 18-minute sample during intraarterial epinephrine to mean during control period.

terial concentration of the measured metabolites might occur. No changes were detectable in arterial concentrations of glucose, lactate, $\mathrm{K}$, or FFA in blood from the subject who received the least of these larger injections, $0.0057 \mu \mathrm{g}$ per $\mathrm{kg}$ of body weight per minute. There was probably an increase in arterial FFA and possibly an increase in arterial lactate concentration in the subject who received the largest rate of injection, $0.025 \mu \mathrm{g}$ per $\mathrm{kg}$ of body weight per minute, and there were possible increases in arterial FFA concentration in one of the remaining two subjects. No other changes were detected in arterial concentrations.

Changes in forearm metabolism in these subjects (Table IV) are of interest from two standpoints. First, they demonstrate the hazards of interpretation of data based solely on a-v differences, and second, they show that the dramatically different effects of epinephrine on peripheral blood flow are accompanied by similar metabolic effects. This suggests that the direction of change of blood flow reflects a direct effect of epinephrine in the blood vessel wall and is not secondary to this changed metabolic environment of the tissues surrounding the blood vessels, as has been suggested.

Changes in a-dv differences of $\mathrm{K}$ and lactate were two to four times greater than the average changes found in the 17 subjects who received the smaller amount of epinephrine. The concentration of lactic acid in venous effluent was greater and that of $\mathrm{K}$ was less in the presence of the larger concentration of epinephrine, but the net vascular response was not vasodilatation.

When the changes in blood flow are taken into account, the uptake or output of glucose, K, lac- tate, and FFA were all within the range of values obtained with the smaller rate of infusion.

Maldistribution of intra-arterial epinephrine. Subject $\mathrm{Cu}$ received $0.002 \mu \mathrm{g}$ per $\mathrm{kg}$ per minute intra-arterially for 30 minutes. Concentration of Evans blue dye in the deep venous plasma was large, but almost no dye appeared in the superficial venous plasma. This sort of maldistribution has been noted previously (see subject E, Figure 5 , reference 9). Blood flow in this subject therefore could not be calculated, but the changes in metabolite concentration are of interest (Table V). The deep forearm bed, which received epinephrine, showed all of the characteristic epinephrine effects. Changes in the superficial bed, where essentially no epinephrine was distributed, were distinctly unlike those to be expected from epinephrine. These data emphasize that, when substances are administered by close arterial technique, their distribution must be monitored by simultaneous injection of an indicator, particularly to avoid misinterpretation of negative results, that is, to distinguish an impotent substance from one that was not delivered to the proper place. It is not enough, as some are doing, to determine only whether or not the indicator is present in venous blood. Uniformity of indicator concentration must be established.

\section{Discussion}

When indicator-dilution methods are used to measure flow as they were in our experiments, with injection into the arterial side and sampling from the venous side of a vascular bed, the response of the dye concentration to altered blood flow is slow. Indeed it is a function of the mean transit time through the system, which is the ra-

TABLE V

Maldistribution: metabolic effects of epinephrine delivered mainly to deep forearm tissues*

\begin{tabular}{lcc}
\hline \hline & $\Delta(\mathrm{a}-\mathrm{dv})$ & $\Delta(\mathrm{a}-\mathrm{sv})$ \\
\hline & $/ m l$ & $/ m l$ \\
Glucose & $-0.10 \mu$ mole & $-0.25 \mu$ mole \\
Lactate & $-0.09 \mu$ mole & $+0.03 \mu$ mole \\
Potassium & $+0.24 \mu \mathrm{Eq}$ & $-0.26 \mu \mathrm{Eq}$ \\
FFA & $-0.05 \mu \mathrm{Eq}$ & $+0.04 \mu \mathrm{Eq}$
\end{tabular}

* Figures represent differences in a-dv and a-sv between the average of three control sets of blood samples and five sets of samples obtained from the tenth to the twentyeighth minute of the intra-arterial infusion. 
tio of plasma volume to plasma flow. During control periods, with plasma flow at about 2.2 $\mathrm{ml}$ per $100 \mathrm{ml}$ forearm per minute and plasma volume at about $5 \mathrm{ml}$ per $100 \mathrm{ml}$ forearm, mean transit time is about 2.3 minutes. It takes a time equal to about 3 mean transit times to move from one steady indicator concentration to a second steady indicator concentration when blood flow changes abruptly from one rate to another at which it remains. When flow doubles, assuming only negligible changes in plasma volume, mean transit time is reduced to a little more than a minute, and our technique requires about $3 \mathrm{~min}$ utes to register the fact fully. If blood flow oscillates with a period less than 2 or 3 mean transit times, our technique can never accurately record the peaks and troughs of blood flow. Although they can record the fact that there were oscillations, venous dye concentrations would be shifted in phase and their oscillations reduced in amplitude compared to those at arterial input, provided the frequency of change in blood flow was not too great. Our technique thus tends to record an average blood flow, damping out oscillations.

When epinephrine is injected into the brachial artery at constant rate, assuming it is diluted quickly by all brachial arterial plasma flowing by it, its concentration is at first relatively high, as it is diluted by the small normal flow. As flow increases in response to epinephrine, arterial epinephrine concentration is reduced by dilution. This would be expected to reduce the response to epinephrine; vasodilatation would become less marked, and blood flow would slow toward normal. But then the concentration of epinephrine in arterial plasma would be increased, and the response to epinephrine would become greater. And so on it would go, producing oscillatory blood flow. Only once did we surely detect this oscillation, but for reasons given above, our method probably lacked adequate temporal resolving power in other instances. There is no question, however, that the effect of epinephrine, administered intra-arterially, was to dilate the forearm vascular bed, and that, with the dose we usually gave, average blood flow remained doubled as long as epinephrine was administered.

This observation apparently is in conflict with the bulk of previous reports. There is general agreement that when blood flow through forearm or calf is measured by venous occlusion plethysmography, large doses of epinephrine cause vasoconstriction. When small doses are given, there is a curious difference between the responses to intravenous and intra-arterial administration. With continuous iv administration there is sustained vasodilatation of vessels through skeletal muscle, but with intra-arterial administration there is only a transient increase in flow that falls to or toward normal despite continuing infusion $(10,18$, 19). Whelan (19) suggested that the immediate, transient vasodilatation was a direct effect of epinephrine but that the sustained vasodilatation, occurring apparently only with iv administration, was mediated by a substance released remotely in response to epinephrine or by a metabolite of epinephrine itself. However, that we found no effect at all when epinephrine was infused intravenously at the same rate at which we infused it intra-arterially, and in which we did find sustained vasodilatation, argues against Whelan's proposal.

Barcroft and Cobbold (20) attributed the sustained increase in blood flow to the rise in venous lactic acid concentration that they found with iv administration of epinephrine, or to some concomitant increase in an unknown humoral agent. They were fortified by the report by Hildes, Purser, and Sherlock (21) that femoral arterial epinephrine infusion caused no change in venous lactate concentration or in glycogen content of the gastrocnemius, which led Barcroft and Cobbold to suppose that the metabolic effects of epinephrine were responsible for its vasodilatation effects or that some other agent was responsible for both. However, de la Lande and Whelan (22) were unable by intra-arterial infusion of $\mathrm{Na}$ lactate to raise forearm blood flow. Furthermore, in our subjects to whom a large dose of epinephrine was administered, the metabolic response resembled that occurring with smaller doses, but there was vasoconstriction or no net vasodilatation.

Intra-arterial epinephrine does cause an outpouring of lactic acid from muscle in man. Besides our own work, two recent reports by Allwood and Cobbold (23) and by de la Lande and his colleagues (24) confirm that venous lactate concentration rises in response to intra-arterial epinephrine. In our subjects, if all lactate output in excess of glucose uptake were attributed to glyco- 
genolysis, there would have been a decrease in muscle glycogen by about $4.5 \mathrm{mg}$ per $100 \mathrm{ml}$ of forearm muscle at the end of 10 minutes. The response of human skeletal muscle to epinephrine, by increasing lactate output, is consistent with that of many other experimental preparations: the perfused limb of the cat (25) and of the dog (26), isolated frog gastrocnemius $(27,28)$, and excised rat diaphragm (29).

There may be no real difference to explain with respect to effects of epinephrine on blood flow. We found a sustained increase in blood flow that we suspect represents a smoothed average of oscillatory flow. Plethysmographers can follow changes in blood flow more quickly. Unfortunately with a single exception, the plethysmographers infused epinephrine intra-arterially so briefly, only for 5 to 10 minutes, that they saw only the first cycle in response to epinephrine. Glover and Greenfield (30) infused epinephrine intra-arterially for more than 15 minutes and by plethysmography measured a return to blood flows higher than normal. Golenhofen (31), by use of a heated thermocouple probe, found that forearm blood flow did indeed oscillate in response to epinephrine and that the oscillations were about a value considerably above that at rest.

Effects reported here on FFA metabolism are those expected from the work of others on effects of iv epinephrine (17) and on effects of epinephrine added in vitro to adipose tissue $(15,16)$.

It has been suggested that the fall in serum $\mathrm{K}$ concentration produced by iv epinephrine (5) is secondary to insulin release induced by hyperglycemia in response to epinephrine. However, de la Lande and associates (24) found that intraarterial epinephrine reduced forearm venous $K$ concentration. The large uptake of $\mathrm{K}$ by forearm muscle in response to intra-arterial epinephrine, in the absence of systemic effect of epinephrine on glucose concentration in our studies, makes this proposal unnecessary and bespeaks a direct effect of epinephrine.

Finally, although we cannot review here in detail the large number of experiments, summarized by Griffith (4) and by Ellis (5), forming the basis of reports that epinephrine increases, decreases, or ignores glucose uptake, our studies are pertinent to this question: What is the action of epinephrine on glucose uptake when epinephrine is delivered to a limb by way of its nutrient artery?

Several reports deal with changes in $a-v$ or capillary-venous glucose differences after subcutaneous administration of epinephrine to man (32-35). These studies ought not to be invoked as evidence, since they ignored the changes in blood flow produced by epinephrine and they ignored the errors introduced by a changing arterial concentration, which must be considered if metabolism is to be measured (7).

Studies of direct epinephrine action on glucose uptake by rat diaphragm use concentrations of 100 to 1,000 times those we produced in the brachial artery (36-39). Groen, Geld, Bolinger, and Willebrands (40) found that epinephrine inhibited glucose uptake by excised muscle only when its concentration was at least $1,000 \mu \mathrm{g}$ per L, possibly because the epinephrine-induced increased glycogenolysis led to such a great increase in glucose-6-phosphate that hexokinase activity was inhibited, a reaction demonstrated by Crane and Sols (41) under special conditions in vitro.

Although only venous concentrations of epinephrine in response to several stresses were reported by Vendsalu (11), the concentration of epinephrine we produced by intra-arterial infusion was probably within the range of those achieved endogenously. Under these conditions glucose uptake by forearm tissues is not inhibited, and it may even be slightly increased. Our observations support the contention of Herman and Ramey (42) that the mechanism proposed by Crane and Sols is of doubtful significance in vivo.

\section{Summary}

1. Effects of epinephrine on forearm blood flow and metabolism were studied in 23 subjects.

2. Continuous intra-arterial infusion of epinephrine for a sufficiently long period and in concentrations that were probably within the range of those achieved endogenously in response to a number of normal stimuli caused $a$ ) immediate and sustained increase in blood flow, $b$ ) glycogenolysis as demonstrated by marked net output of lactic acid from deep forearm tissues in excess of glucose uptake, c) no significant change in glucose uptake by deep forearm tissues, $d$ ) potassium uptake, clearly not secondary to glucose uptake or to endogenous insulin release, and $e$ ) output of 
free fatty acids from superficial and deep forearm adipose tissue.

3. Continuous intravenous infusion of epinephrine at the same rate as that given intra-arterially had no effect on forearm blood flow or metabolism.

4. These results appear to make unnecessary past efforts to explain an apparent difference in response of blood flow to iv compared to intraarterial administration of epinephrine. Small, but effective, concentrations of epinephrine in arterial plasma, whether given iv or intra-arterially, increase blood flow through muscle.

5. Continuous intra-arterial infusion of epinephrine at a rate three to ten times that used in experiments summarized in paragraph 2, above, caused only transient increase in blood flow followed by either prolonged reduction or no net change in blood flow. However, metabolic effects of the larger rate of infusion of epinephrine were similar to those of the smaller rate of infusion. In particular, venous lactate concentrations were even greater than in those experiments in which net vasodilatation occurred. It is, therefore, difficult to attribute the vasodilating response to epinephrine as secondary to increased lactate concentration.

\section{Acknowledgments}

We are indebted to those who volunteered for these experiments and to Misses Louise Margolet and Sara Ann Verplanck, Mrs. James Cullen, and Mr. Donald Coleman for technical assistance.

\section{References}

1. Griffith, F. R., Jr. Adrenaline, Adrenergic-Sympathomimetic and Adrenolytic-Sympatholytic Drugs. Buffalo, 1956.

2. Fredrickson, D. S., and R. S. Gordon, Jr. Transport of fatty acids. Physiol. Rev. 1958, 38, 585.

3. Barcroft, H., and H. J. C. Swan. Sympathetic Control of Human Blood Vessels. London, Edward Arnold, 1953, and Baltimore, Williams and Wilkins, 1953.

4. Griffith, F. R., Jr. Fact and theory regarding the calorigenic action of adrenaline. Physiol. Rev. 1951, 31, 151.

5. Ellis, S. The metabolic effects of epinephrine and related amines. Pharmacol. Rev. 1956, 8, 485.

6. Baltzan, M. A., R. Andres, G. Cader, and K. L. Zierler. Heterogeneity of forearm metabolism with special reference to free fatty acids. J. clin. Invest. 1962, 41, 116.

7. Zierler, K. L. Theory of the use of arteriovenous concentration differences for measuring metabo- lism in steady and non-steady states. J. clin. Invest. 1961, 40, 2111.

8. Andres, R., G. Cader, and K. L. Zierler. The quantitatively minor role of carbohydrate in oxidative metabolism by skeletal muscle in intact man in the basal state. Measurements of oxygen and glucose uptake and carbon dioxide and lactate production in the forearm. J. clin. Invest. 1956, $35,671$.

9. Andres, R., K. L. Zierler, H. M. Anderson, W. N. Stainsby, G. Cader, A. S. Ghrayyib, and J. L. Lilienthal, Jr. Measurement of blood flow and volume in the forearm of man; with notes on the theory of indicator-dilution and on production of turbulence, hemolysis, and vasodilatation by intravascular injection. J. clin. Invest. 1954, 33, 482.

10. Duff, R. S., and H. J. C. Swan. Further observations on the effect of adrenaline on the blood flow through human skeletal muscle. J. Physiol. (Lond.) 1951, 114, 41.

11. Vendsalu, A. Studies on adrenaline and noradrenaline in human plasma. Acta physiol. scand. 1960, 49 (suppl. 173), 1.

12. Cohen, G., B. Holland, J. Sha, and M. Goldenberg. Plasma concentrations of epinephrine and norepinephrine during intravenous infusions in man. J. clin. Invest. 1959, 38, 1935

13. Dole, V. P. A relation between non-esterified fatty acids in plasma and the metabolism of glucose. J. clin. Invest. 1956, 35, 150.

14. Andres, R., G. Cader, P. Goldman, and K. L. Zierler. Net potassium movement between resting muscle and plasma in man in the basal state and during the night. J. clin. Invest. 1957, 36, 723.

15. Gordon, R. S., Jr., and A. Cherkes. Production of unesterified fatty acids from isolated rat adipose tissue incubated in vitro. Proc. Soc. exp. Biol. (N. Y.) 1958, 97, 150.

16. White, J. E., and F. L. Engel. A lipolytic action of epinephrine and norepinephrine on rat adipose tissue in vitro. Proc. Soc. exp. Biol. (N. Y.) 1958, 99, 375.

17. Gordon, R. S., Jr., and A. Cherkes. Unesterified fatty acid in human blood plasma. J. clin. Invest. 1956, 35, 206.

18. Allen, W. J., H. Barcroft, and O. G. Edholm. On the action of adrenaline on the blood vessels in human skeletal muscle. J. Physiol. (Lond.) 1946, $105,255$.

19. Whelan, R. F. Vasodilatation in human skeletal muscle during adrenaline infusions. J. Physiol. (Lond.) 1952, 118, 575.

20. Barcroft, H., and A. F. Cobbold. The action of adrenaline on muscle blood flow and blood lactate in man. J. Physiol. (Lond.) 1956, 132, 372.

21. Hildes, J. A., S. H. Purser, and S. Sherlock. The effects of intra-arterial adrenaline on carbohydrate metabolism in man. J. Physiol. (Lond.) 1949, 109, 232. 
22. De la Lande, I. S., and R. F. Whelan. The role of lactic acid in the vasodilator action of adrenaline in the human limb. J. Physiol. (Lond.) 1962, 162, 151.

23. Allwood, M. J., and A. F. Cobbold. Lactic acid release by intra-arterial adrenaline infusions before and after Dibenyline, and its relationship to bloodflow changes in the human forearm. J. Physiol. (Lond.) 1961, 157, 328.

24. De La Lande, I. S., J. Manson, V. J. Parks, A. G. Sandison, S. L. Skinner, and R. F. Whelan. The local metabolic action of adrenaline on skeletal muscle in man. J. Physiol. (Lond.) 1961, 157, 177.

25. Lundsgaard, E., N. A. Nielsen, and S. L. Ørskov. On the utilization of glucose and the formation of lactic acid in the isolated hind limb preparation. Skand. Arch. Physiol. 1939, 81, 20.

26. Geiger, E., and E. Schmidt. Mobilisierung des Muskelglykogens durch Adrenalin. NaunynSchmiedeberg's Arch. exp. Path. Pharmak. 1929, 143, 321.

27. Wesselkina, W. M. Beeinflusst Adrenalin den Einund Austritt von Milchsäureionen aus den Muskeln? Z. ges. exp. Med. 1931, 79, 630.

28. Hegnauer, A. H., and G. T. Cori. The influence of epinephrine on chemical changes in isolated frog muscle. J. biol. Chem. 1934, 105, 691.

29. Walaas, O., and E. Walaas. Effect of epinephrine on rat diaphragm. J. biol. Chem. 1950, 187, 769.

30. Glover, W. E., and A. D. M. Greenfield. The effects of prolonged intra-arterial infusions of adrenaline and noradrenaline on the blood flow in the human forearm. J. Physiol. (Lond.) 1962, 160, 4P.

31. Golenhofen, K. Sustained dilatation in human muscle blood vessels under the influence of adrenaline. J. Physiol. (Lond.) 1962, 160, 189.

32. Wiechmann, E. Über die Glukosepermeabilität der peripheren Gewebe beim Adrenalindiabetes. Dtsch. Arch. klin. Med. 1927, 154, 296.
33. Cori, C. F., and G. T. Cori. The mechanism of epinephrine action. IV. The influence of epinephrine and lactic acid production and blood sugar utilization. J. biol. Chem. 1929, 84, 683.

34. Somogyi, M. Studies of arteriovenous differences in blood sugar. V. Effect of epinephrine on the rate of glucose assimilation. J. biol. Chem. 1950, 186, 513.

35. Van Itallie, T. B., and W. B. A. Bentley. Glucagon-induced hyperglycemia as an index of liver function. J. clin. Invest. 1955, 34, 1730.

36. Walaas, E. The effect of adrenaline on the uptake of glucose, mannose, and fructose in the rat diaphragm. Acta physiol. scand. 1955, 35, 109.

37. Candela, R. R., and J. L. R. Candela. Influencia de la adrenalina sobre el consumo de glucosa por el diaphragma aislado de rata. Med. Segur. Trab. 1955, 3 (suppl. 11), 21.

38. Riesser, O. Über Glykogensynthese im überlebenden Rattenzwerchfell und ihre Beeinflüssung in vitro durch Hormone und Vitamine. Biochim. biophys. Acta (Amst.) 1947, 1, 208.

39. Sutherland, E. W. The effect of epinephrine and the hyperglycemic factor on liver and muscle metabolism in vitro in Phosphorus Metabolism, W. D. McElroy and B. Glass, Eds. Baltimore, Johns Hopkins, 1952, vol. 2, p. 577.

40. Groen, J., H. v. d. Geld, R. E. Bolinger, and A. F. Willebrands. The anti-insulin effect of epinephrine. Its significance for the determination of serum insulin by the rat diaphragm method. Diabetes 1958, 7, 272.

41. Crane, R. K., and A. Sols. The association of hexokinase with particulate fractions of brain and other tissue homogenates. J. biol. Chem. 1953, 203, 273.

42. Herman, M. S., and E. R. Ramey. Epinephrine action on glucose uptake by rat diaphragm; effect of ionic composition. Amer. J. Physiol. 1960, 199, 226. 